\title{
Reimagining "Collaborative Exploration"-A Signature Pedagogy for Sustainability in Early Childhood Education and Care
}

\author{
Elin Eriksen Ødegaard
}

check for updates

Citation: Ødegaard, E.E.

Reimagining "Collaborative

Exploration"-A Signature Pedagogy for Sustainability in Early Childhood Education and Care. Sustainability 2021, 13, 5139. https://doi.org/ $10.3390 /$ su13095139

Academic Editor: Clemens Mader

Received: 22 February 2021

Accepted: 28 April 2021

Published: 4 May 2021

Publisher's Note: MDPI stays neutral with regard to jurisdictional claims in published maps and institutional affiliations.

Copyright: (C) 2021 by the author. Licensee MDPI, Basel, Switzerland. This article is an open access article distributed under the terms and conditions of the Creative Commons Attribution (CC BY) license (https:// creativecommons.org/licenses/by/ $4.0 /)$.
KINDknow-Kindergarten Knowledge Centre for Systemic Research on Diversity and Sustainable Futures, Western Norway University of Applied Sciences, 5063 Bergen, Norway; eeo@hvl.no; Tel.: +47-55-585932

\begin{abstract}
The purpose of this article is to identify the components and features of a signature pedagogy for sustainability in early childhood education and care to respond to the call for tradition and innovation in early childhood education. Collaborative exploration is proposed as a pedagogical strategy, a relevant mode of action for sustainable practice. This is a conceptual article that recalls the origins of early childhood pedagogy and uses an exemplary empirical narrative from a recent study to illustrate collaborative exploration in an early childhood educational setting. The outlining of the key features of collaborative exploration is furthermore inspired by dialogism. This article provides an argument against mainstream understandings of pedagogical strategies for early childhood education, which are often based on instrumental program approaches, emphasizing the transmission of information in a traditional classroom setting. It is argued that practices of collaborative exploration are embodied in a way that is aligned with the tradition of child-centered early years pedagogy. Moreover, they are crucial to ensuring that all participating children are given responsive support to become members of ecologically, socially and culturally sustainable educational practices, strengthening children's resilience and agency and inclusive education. The article's value lies in its potential to support teachers' thinking and practice in recognizing and articulating collaborative exploration as a signature pedagogy.
\end{abstract}

Keywords: signature pedagogy; collaborative exploration; social sustainability; pedagogical style; early childhood education and care

\section{Introduction}

Collaborative exploration holds the promise of contextual responsiveness to children's embodied enculturation, meaning-making and formation in play and development in the field of early childhood education and care (ECEC) [1-3]. It is a means to the ultimate objective of reimagining early childhood education and care for social sustainability in the future we want. It is vital to ECEC that we pay attention to the long-term puzzle of inquiry, namely, how to educate the young child for the future, when all we know is the past and present. As teachers, we anticipate the future for the child. We advise, teach, invite and share knowledge without knowing if these forms of knowledge or the content of it will be meaningful and of use for the child in the future. The child itself will be in a position of making meaning in the world in which they live, gradually growing understandings, knowledge and skills through the embodied exploration of the human and non-human environment and through ludic play and exploration. For the teacher to await the future before giving advice, teaching, inviting or sharing with the child would be irresponsible and lead to brutal childhood experiences. A responsible education requires maneuvering responsively to the child's situation with uncertainty in mind [4]. We need to navigate unknown futures with wisdom and envision the future of our children.

As a contrast to the promise offered by researchers envisioning collaborative play explorative approaches, ECEC has recently been under pressure to support a lesser holistic 
and contextual approach in education [1]. By focusing merely on the development of children's cognitive and academic skills, which are deemed fundamental for success in school and later in life, knowledge about the value and benefits of play and exploration for children's joy, wellbeing, resilience and perseverance, a driving force in problem-solving and engagement in staying alive, are overlooked. This "down-schooling" pressure has resulted in the influx of indicators supporting the achievement of academic learning goals and has strengthened the Anglo-Saxon educational tradition, which reinforces a narrower understanding of children's development and play-based learning $[5,6]$. This approach has expanded globally, including in the Nordic countries, replacing the more holistic approach in ECEC $[7,8]$. An increasing number of children worldwide do not develop mature forms of play before school age, as confirmed by the results of an international review in 16 countries [9]. This "down-schooling" tendency has resulted in inappropriate programs and practices in ECEC, threatening children's holistic development [5], as it downplays or ignores children's natural inclination to move, play and explore.

From the perspective of sustainable futures, it is urgent to talk about the importance of the pendulum swinging back to acknowledge play as a serious driver of exploration, as play brings meaning and a state of flow to activities [10]. Play is part of human nature. It allows us to imagine new possibilities and situations that never existed before, and most importantly, it holds the promise of making the future better. The process of play prepares us for the unexpected and creates conscious and subconscious contingency plans that are agile and ready to adapt to the changing landscape. Most importantly for this article, play is an intrinsically motivated experience evolving around explorative activities, triggering playfulness and endurance in activities, and it does not belong to children alone [11].

Therefore, a premise of this article is the obvious fact that teachers and children in educational settings are sensational human bodies entangled in a world of nature and culture. This obvious premise needs to be addressed, as mainstream education in the Western world is primarily accustomed to educational approaches that target our senses of sight and hearing, while smell, taste and touch have been considered the "lower" senses and not given a place ([12], p. 270). ECEC needs to respond to the child as a whole body, as found in historical documents on the origin of ECEC as well as in contemporary research $[1,6,13]$, frameworks for early childhood and in research.

In contrast to the predominant main narrow approaches, this article proposes, in the name of sustainability in ECEC practices, that we must look for and articulate approaches in line with embodied and relational epistemologies and paradigms that allow continuous inquiry and local sensitivity. Thus, the purpose of this article is to identify the components and features of a signature pedagogy for sustainability in ECEC to respond to the call for tradition and innovation in early childhood education.

Peter Moss [14] argues for the necessity of a post-fundamentalist approach to ECEC, where quality works need to be contextualized, recognizing cultural diversity and aspects of time, space and place. Rather than considering a straightforward solution to ECEC pedagogy, this article presents examples and reasonings following paradigms allowing nonlinear age- and play responsiveness. Such approaches take cultural-historical perspectives into account to elaborate knowledge of teachers' styles and positioning ECEC pedagogy, where sensation [1] and teachers' responsiveness to play [15] and exploration are in focus. Following a cultural-historical approach, ECEC researchers have examined what happens when teachers position themselves within the frame of a play word and what a joint interaction between children and teachers leads to in play [16-18]. These approaches are an alternative to the "down-schooling" approach, valuing sense-making, play and exploration. They espouse a broader view of child development and learning by emphasizing the cultural diversity and resources and embodied practices in which children partake.

Such knowledge is crucial if future policy and practice are to achieve the goal of equity and social sustainability. The Sustainable Development Goals (SDG) include a focus on high-quality education. For example, Goal 4 reads, "Ensure inclusive and quality 
education for all and promote lifelong learning" ([19], p. 19). Goal 4.2 specifically focuses on ECEC: "By 2030, ensure that all girls and boys have access to quality early childhood development, care and pre-primary education so that they are ready for primary education" ([19], p. 19). Related to this statement, it is essential to view "readiness for school" from a broad perspective to avoid a narrow "ready for school approach" to early education [20]. It is crucial for children's all-around health that care, play and learning are connected to the context in which they live. Ideally, early childhood development services must be provided holistically across all relevant sectors to enable young children to thrive $[20,21]$. While the dominant discourse holds that readiness for school implies training on a set syllabus and rote learning, such approaches are not mentioned in the SDGs. Arguably, Goal 4 can be interpreted as a proposition to learn from holistic approaches to early childhood education. Such a holistic understanding of Sustainable Goal 4 is already implemented in ECEC research, both in child- and play-responsive educational approaches, e.g., [15] and in ecological "common worlds" approaches, where nature and culture are considered entangled [22]. These approaches share a wide relational paradigm that this article follows.

In what follows, I first give a brief introduction of the concept of signature pedagogy and from there draw a line to the first philosophical efforts to articulate exploration of a holistic child-responsive ECEC pedagogy. Second, I present earlier findings from previous and contemporary empirical studies on play, learning and exploration and show how they are interrelated, but not the same. Third, I present an example to illustrate collaborative exploration practice in an early childhood setting. The analysis illustrates the components, conditions and features of collaborative exploration and can support teacher's understandings and strategies for collaborative explorative practices.

Following Mikhail Bakhtin, I adopt an organic and relational epistemological paradigm. Based on this way of thinking, I build an argument that collaborative exploration has been and includes features of an early childhood teacher's ideal practice. This does not mean that this signature is and should be present in all activities. Defining the features of what collaborative exploration entails will serve as a powerful driver of sustainable education. The premise of the child being a sensational human body entangled in a world of nature and culture, where education needs to be responsive to the child. This means that both historical and future orientations will be necessary.

\section{What Is a Signature Pedagogy of ECEC?-Introducing the Research Questions}

A signature pedagogy is, according to Lee Shulman ([23], p. 55), "a set of assumptions about how best to use certain forms of knowledge and skills". It is possible to identify the signature pedagogy of a profession by analyzing (1) a surface structure, specific ways of asking and answering, ways of approaching, taking initiative and withdrawing. We can also see a signature pedagogy in (2) a deep structure-a set of assumptions about how to use knowledge-and in (3) an implicit structure-ethical attitudes, values and dispositions. It is also possible to identify it (4) through an awareness of what it is not. Shulman is renowned for identifying the signature pedagogy of teacher education [24]. In his research, Shulman identified effective and wise practices in the teaching profession. He differentiated between wise practice and ignorant practice and advocated for deeply enhancing wise practices [23].

Inspired by this encouragement to look for wise practices, I examine Shulman's four structures to ascertain a set of features depicting pedagogical practices that will identify a signature pedagogy of ECEC that I also believe to be a sustainable pedagogical practice. I, therefore, inquire into the deep structure by asking the following question: What are the assumptions regarding how early childhood teachers use knowledge? I answer this question by examining the influential philosophical, psychosocial text and contemporary studies that shed light on the underpinnings of ECEC practice. Furthermore, I study the ethical attitudes, values and dispositions found and the surface structures of teacher behavior by asking what the features of teacher practices are when engaging in explorative activities with children. I illustrate an answer to this question through an analysis of an exemplary case. 
Shulman discovered that despite institutional differences, teacher-students learned to think like professional teachers across institutions. Students studying to be kindergarten teachers will learn about child development, play and learning, the origin of ECEC and the current frameworks that guide early childhood institutions today. They will also obtain knowledge in a particular area. Shulman found that, while different professional universities had their own profiles and priorities, their public mission statements were alike, often a commitment to justice and fairness [23].

In looking for assumptions regarding these underpinning structures and values, studies on Norwegian kindergarten teacher education can serve as a mirror to his findings. Through a series of studies (2014-2016), it was found that common motivations of kindergarten teacher students (N-6410) for studying to become a teacher in ECEC were intrinsic values, such as the joy of working with children, finding meaning in life by supporting children and being inspired by children. They scored very low on extrinsic motivation, so salary, status and bonuses were not important for their career choice in the kindergarten teacher profession [25]. Such idealistic motivations resonate with the first philosophical efforts of articulating a holistic child and nature-responsive ECEC pedagogy. Therefore, let us turn to the intrinsic underpinning of values and features found in early attempts to find new scientific approaches based on a balance between nature, man and society.

\section{Froebel as Philosophical Underpinnings of a Holistic Approach to ECEC}

The 17th century was characterized by rapid developments in science. Cartesianism (dualism of mind and body) resulted in a tendency to make man the ruler of nature [26]. In the work of the pedagogue Johan Amos Comenius, there is a strong emphasis on the need for freedom, and his legacy is contrary to Cartesianism: a holistic conception of professional education used for creating various experience, leading students of professions to appropriate solutions to diverse situations they will encounter in their work. In Comenius's Orbis Sensualium Pictus, he made an effort, through the encyclopedian genre, to enrich children's understanding by presenting a wide range of sciences. A visual representation of the world inspires children to use their senses [27]. Friedrich Froebel opposed the Cartesian view of the mind as being wholly separate from the corporeal body, where sensation and the perception of reality are thought to be the source of untruth and illusions, in his philosophical and didactic ("didaktik" in German) approach to educating the youngest of mankind, the children.

Froebel (1782-1853) practiced as a teacher, a teacher educator and a writing philosopher. In his autobiography, written as a long letter to the Duke of Meiningen, he writes the following: "To stir up, to animate, to awaken, and to strengthen, the pleasure and power of the human being to labour uninterruptedly at his own education, has become and always remained the fundamental principle and aim of my educational work" ([28], p. 11). Here, he states his educationalist signature as an engaged individual, driven by and encouraged by inner strength. This message of bringing life-joy into education is explained by Froebel himself in his autobiography and by his biographer, Bertha Wulff [29], as a building journey and a drive to make childhood life more human than his own childhood memories. His statement can be understood as a refutation of his own strict upbringing and first schooling by his father, the local pastor in his home village.

According to Froebel's different "didaktik", the child should have a teacher who encourages imagination and invites curiosity about different forms life can take, a dwelling of lived harmony with the cycles of nature and the cosmos. Froebel himself articulates his "didaktik" for the educator (here in the meaning of both teacher and parent) in The Pedagogics of Kindergarten [30].

This was written as a guide for parents, nurses and "kindergarteners" to prevent adults from destroying the child's "faith and confidence" ([30], pp. 58-59). From these extracts, we can see how Froebel himself was driven by an urge to bring education to life through engagement in the self, the child and the ecosystem in which we all exist. His practice was that of an engaged teacher broadening the child's perspectives and 
experiences through play, games, songs, dances, stories and crafts and engaging with nature and the environment.

"Kindergarten" in Froebel's vision meant "a garden for children", where children experience the cycles of nature and the cosmos of the ecological environment. It also meant "a garden of children", a space where children could meet peers to play. In his vision of the kindergarten, the teacher could learn from the children, and the children could learn from the teacher. This is evoked in his well-known phrase: "Kommt Lass Uns Unsern Kindern leben" (Come let us live with our children) [31]. This slogan expresses an encouragement to be responsive to the child, a view of the child and of adults, whether adult or teacher, praising joint engagement in children's lives.

In a study of the English translations of "Education of Man" [31], we found that Froebel used synonyms for exploration, such as play and discover, and description of pedagogical practice. What is of special interest to our study of signature pedagogy as collaborative exploration is his concept of "the invisible third". He explains "the invisible third" as a space where the pedagogics of kindergartens lie in a practice where the teacher and child create a common ground of curiosity, attention and exploration. A pedagogy for explorative practices will always have "something worth exploring", such as content, what Froebel calls "the invisible third". Froebel imagined that certain kinds of play materials were shaped in line with the universal shapes of geometry, what he called "gifts", which would teach the child to discover the connection between human life and life in nature. In turn, the gifts would create a bond between the adult and the child, who play with them; this bond is referred to as "the invisible third".

Even if Froebel himself did not use the concept of exploration to describe the pedagogics of kindergartens, those who later translated and actualized his text into contemporary times seem to agree upon this "didaktik" as collaborative and explorative, as pointed out by the Froebel Institute's 200th-year celebration of. Here, The Froebel Institute gives examples of how the pedagogic of Froebel was practiced. Geographical knowledge was acquired by walking along the riverbed from the source of the flow to a larger stream, by sitting on top of a hill and making a map: "Such exploration extended to plants, trees, insects, birds and stones, each studied minutely" ([32], p. 6). Such interpretations of Froebel are also found in the research of experts on Froebel when outlining Froebel's legacy in children's play and learning. Kindergarten play can be considered as exploring, which materials allowing children to engage in activity, and through exploring the play material, children develop emergent understandings [33].

Activity, imagination and creativity are words associated with exploring, and they are relevant in establishing kindergartens as pedagogical institutions as well as indications of a possible bond between the teacher and child while exploring the play material ("gifts"). In The Pedagogics of the Kindergarten [30], Froebel describes the importance of considering the presence and absence of an object and how this triggers curiosity and imagination. Froebel argues that the teacher should perform repetitions of activities, but it is important to vary the way of playing with the same object; for example, as outlined in The Pedagogics of the Kindergarten [30], by hiding a cube in her hand while she sings to the child: "I see now the hand alone. Where, oh, where can the cube be gone" ([30], p. 84). With gaze and attention, the mother (teacher) leads the child to her hand and the child's hand. The mother (teacher) continues by opening the concealing hand and singing, "Aha! Aha!-My hand has hid the cube with care, while you looked for it everywhere. See it is here! Look at it dear!" ([30], p. 84). The play continues by only concealing parts of the cube, and, in these ways, by singing, hiding and concealing, Frobel argues that the mother (teacher) is bringing the child into more intimate connection with the expression of a cube [31]. He carefully describes how the song, the playful attention, the encouragement of imagination and the close relation between the mother (teacher), the child and the object are described in the activity.

With the guidance of Froebel's philosophy of "the invisible third" and descriptive "didaktik", especially in The Pedagogics of the Kindergarten [30] as well as in later Froebel 
interpretations, we have a clear historical model of a pedagogy that is the language of 2021 can be conceptualized as "collaborative exploration". Froebel offers a "didaktik" and a call for education to be responsive to and a part of the child's world; he cannot guide us on the more specified understanding of exploration per se.

The above inquiry into the pedagogy of Froebel reveals certain specific ways of acting; the knowledge of the child and the environment is crucial, and the mode of the teacher is to be engaged in the pedagogical act, with joy and excitement to learn from the child's interest or lead the child to new discoveries. These are the assumptions about how the early childhood teacher uses knowledge guided by Froebel. We can also find strong ethical attitudes and values, such as a deep recognition of and respect for the child and the ecosystem (holistic cosmos) in which the teacher and child live. The features of the teacher's pedagogical style that stand out are playfulness, self-awareness, walking alongside children to learn and discover and introducing children to the natural shapes and forms of lives. It is also possible to identify what a signature pedagogy, according to Froebel's philosophy and "didaktik", is not. Froebel contradicts any punishment or instrumental rewarding of the child. Following Froebel, punishing children is not the signature of a kindergarten teacher's practices, nor is a strict transmitting of orthodox knowledge from teacher to child.

As shown above, Froebel gives very explicit advice and descriptions of what can be called "collaborative exploration". Nevertheless, an extended inquiry will further sustain the conceptualization of the concept of "exploration" as collaborative and the promise this concept holds for understanding the current complex situations of kindergartens and the signature pedagogy of contemporary kindergarten practice.

\section{Conceptualizing "Exploration" in the Wider Context of ECEC}

The verb "to explore" seems to have generally positive connotations. The commonly shared meaning could be that to explore means to connect humans with the elements of the world and beyond. As the explorer and astronaut Buzz Aldrin wrote, "The urge to explore has been the primary force in evolution since water creatures began to reconnoiter the land ... / / . . Living systems cannot remain static; they evolve or decline. They explore or expire. The inner experience of this drive is curiosity and awe-the sense of wonder. Exploration, evolution, and self-transcendence are only different perspectives on the same process" ([34], p. 1). The famous astronaut, the second man on the moon, notes that the inner drive of exploration is "curiosity and awe-the sense of wonder". He argues that exploration is the drive of evolution and, at the same time, the drive to expand personal boundaries. Self-transcendence potentially includes experiences of spiritual ideas, such as considering oneself an integral part of the universe. This same sense of wonder, the urge to explore, was also illustrated in the vignette above.

Exploration is also used as a positive verb in early childhood frameworks (e.g., [35] Specifically, it is a concept used to indicate the nature of children's activities in kindergarten, often as a word connected to play and to learn. A study of the underpinning structures of play and learning in four guidelines and frameworks (Confucius and Nordic), China, Hong Kong, Finland and Norway, revealed that play and learning are the dominant concepts in all frameworks and that learning is described as multifaceted in all of them. Despite cultural differences, there are strong similarities on a framework level, as all cultures aim to cultivate all-around development. The differences found were that Confucius countries pay more attention to learning to know, while Nordic countries emphasize learning to do and learning to be [35]. Exploration can be a mode of action indicating learning to do. If so, this study indicates that Nordic frameworks guide teachers to activities characterized as collaborative exploration to a larger extent than Confucius frameworks.

Exploration in practice can also realize such idealistic models of the process in activities; however, exploration can also be experienced as harmful. For example, when values are disconnected or disputed, exploration can be exploitive, such as when the topic, land or activity invades or destroys others. Harmful exploration can be observed in early years institutions, as described in the study of meaning-making in play narratives between 
toddlers. Ongoing meaning-making processes, which can be described as explorations in-between joy and fear, were observed between children when they explored what happens when the lights are turned off and on repeatedly in the playroom and when sudden switches between dark and light occur. When some children started to cry, the child in control of the switch was more in a mode of exploration-listening to what happens when it gets dark and then what happens when it gets light again [36]. This activity happened in what seemed to be a play activity, but the one child in charge of the switch actually spoiled the play activity for the other children. A similar ambivalence and complexity of explorative activities were found in a case study of children's play exploration. Ruth Ingrid Skoglund analyzed how children explore relations that she described as ongoing inclusion and exclusion processes in play activities, which can seem like a complex exploration of power relations [37]. These studies offer narratives where exploration can lead in skewed directions, requiring teachers' responses to intervene and provide guidance.

The work of Corinne Hutt and her team has brought new understandings to the interrelationship between play and exploration [38-40]. Based on empirical observations of children's play, they created a taxonomy of play, attempting to categorize play into different types. They identified the following three main categories of play: (1) epistemic play, within which children learn and explore the world and its properties; (2) ludic play when children are using their imaginations but are not necessarily learning; and (3) games with rules, that is, organized activities. Hutt and her team [39] described how modes of engagement vary over time, even with the same toy. They characterized the first encounter with a toy as epistemic engagement, signified by a serious focus on an intense and attentive inquiry. Meanwhile, they categorized exploration as a subdivision of epistemic behavior, classified in investigation and inspection. When children begin to understand the toy, they change to what Hutt calls "ludic" engagement, which is more relaxed, and they use their understanding of the toy in their play activity. Ludic behavior is, according to these researchers, subdivided into two main categories: symbolic or fantasy play and play with repetitive elements. Symbolic play may be further subdivided according to the focus of the fantasy. The pretense can be directed toward an object, such as when a child arranges a row of chairs that serves as bus seats (fantasy object), or it may involve a character shift, such as when a child steps into the role of a bus driver. Repetitive play implies monotonous patterns, such as when a child uses the pail and shovel to make the same shapes in the sandpit over and over again. If the child adds some new elements, such as bringing a piece of wood to stabilize a series of pail-sand forms into construction in the sandpit, it can be called innovative. When adding new material into the sand construction, the child is combining skills. There is an extension and a development in the play. When children's activities are continuously repetitive, and no novel objects or changes of patterns occur over time, the play, according to Hutt, becomes perseverative, with a risk of being static or manic ([39], p. 286).

The teacher can respond to the situation with awareness of previous situations, and afford a new object, or a new idea, to the child. Hutt and her team gathered groups of young children to experiment with a special box, which had been fitted with different devices so that a sound or light would be released following certain manipulations. Hutt's research on children's play with a "novel object" led the team to suggest that children would play in exploratory or experimental ways for a while when afforded a novel object. When they were playing with a novel object, their mode of action indicated a question: "What does this do?" Hutt [39] saw this as an explorative activity, as the "epistemic" phase of the play. If the child continued the activity after exploring and getting to know the novel object, the child would probably then use what they had discovered to play in fun or "ludic" way, as if asking, "What can I do with this?"

Of relevance for this article is that if a situation of repetitive play is observed by the teacher, it can arouse a teacher's initiative to collaborate with the child. When a teacher takes such an initiative, which endures through the activity with the child and the novel object, the result will be collaborative exploration. The teacher's involvement makes a 
difference in the activity. The point is not for the teacher to take over, but rather, on one hand, to highlight the opportunity to expand the child's knowledge through their exploration of novel objects or ideas, and, on the other hand, to enrich and extend the opportunities to play in a ludic manner, have the child take control and agency of the novel object or idea.

The inquiry into the ground-breaking research of Corrine Hutt and her team reveals certain features of play, as they make a distinction between exploration as the epistemic and serious face in play, characterized by a serious mode, and symbolic play, as a ludic form of play, characterized by a mode of joy and relaxation. Both will motivate the endurance of an activity. In fact, Hutt challenges the common understanding that "play is the work of children", meaning that play is natural - that it is for every child. On the contrary, her research on brain activity in various activities showed that play occurs only in certain exceptional circumstances. She claims that many animals and children do not play in the ludic sense at all ([39], p. 291). Furthermore, she argues that play is a luxury and that, for play to occur, the person must be motivated to arouse feelings. There is a parallel between seeking stimulation and play. Both are accompanied by positive effects, and they both involve exploration, investigation and manipulation of the environment. Her distinction between play and exploration is not as clear. Hence, are there any distinctions between play and stimulus-seeking behavior as exploration? The answer she gives is that play is clearly a stimulus-seeking behavior, yet not all stimulus-seeking behavior is play. She concludes with the notion that the primary function of play is to keep the neural and behavioral systems primed and active and that the absence of play, whether in an epistemic or a ludic sense, makes it likely that the individual will become inattentive and drowsy, possibly leading to sleep.

Bringing these distinctions into a perspective of pedagogical impact for the teacher makes sense. Play modes of any kind, whether in an epistemic, gaming or ludic sense, are necessary for growth, living and development. Knowledge about variations of play modes and typologies of play is important for early childhood teachers. Observing and identifying whether children play, and, if they do, in what ways, can alert teachers to take initiatives in the pedagogical act to enhance the play duration and engagement and break stereotypical patterns of behavior, providing a stimulus to the activity and collaborating with the children to arouse effects and thereby extend the children's endurance and positive engagement in life. Children's explorations are, according to recent studies on play explorations, an inductive process, requiring openness and flexibility, creativity and imagination, where they search for new ideas or perspectives [2]. According to our own studies of children's exploration in educational settings, it needs to be understood in relation to pedagogical cultures [3].

Through a recent case study, seven features encouraging and supporting co-explorative practice were identified. The following seven features arose in the analysis following a series of transitional events in a kindergarten over eight years while encouraging and supporting a collaborative explorative practice [41]:

1. Institutional anchoring of content that opens the way for exploration, transformation and expanding content;

2. Personal engagement by working with formative and bodily awareness and valuing personal knowledge and story;

3. Local anchoring of content by working with the local community; plan for and act upon cultural customs;

4. Imagination and creativity by working in ways that include planning, new ideas and theorizing;

5. Initiations, responses and follow-ups inviting children and families into personal stories and increasing their awareness of local and global artifacts;

6. Collaborative investigation through common engagement, staff and children investigating questions deriving from events, activity and projects; 
7. Establishing a conversational genre for exploration as dialogical and philosophic approaches in a participatory space of action.

The pedagogical style of collaborative exploration, which in this article I call the signature of the ECEC teacher, which best supports children's exploration, refers to modes of action by the teacher that afford children the possibilities for initiatives that are adopted and developed through interaction. This mode of positioning, where the teacher responds and follows up on children's emergent explorations, will be habituated in open pedagogical cultures, where explorative and transformative modes of actions are valued by governance and leadership, anchored in institutions. A crucial characteristic found in the abovementioned case study was the personal engagement of the teacher.

Hence, far, I have examined the cultural underpinnings of a signature pedagogy for the early years by drawing on a selection of early philosophical, psychological and contemporary studies that shed light on the values and the deep structure of an early childhood educator's signature pedagogy. In the following, I will seek to shed light on what constitutes a personal engagement in pedagogy.

\section{Adding a Dialogic Epistemological Framework to Indicate the Teacher's Style of Collaborative Exploration}

A Bakhtinian framework can add understandings relevant for pedagogical practices, the enactment of exploration as dialogical engagement and the drivers for engagement in pedagogical activities. Mikhail Bakhtin states that all the diverse areas of human activity involve using language as diverse as the areas of human activity. He mentions the following three aspects of utterances in language: thematic content, style and compositional structure. These are inseparably linked to the whole of the utterance and are equally determined by the specific nature of the particular sphere of communication: "Each separate utterance is individual, of course, but each sphere in which language is used develops its own relatively stable types of these utterances. These we may call speech genres" ([42], p. 60). Bakhtin's notion of speech genres must not be understood as merely analyzing speech acts. Following Per Linell's understanding of dialogism, a speech genre must include speech as body [43] and shown in styles and modes of actions and positionings. A pedagogical style is, therefore, a continuous practice, although it will also include cracks, stops or turning points [44].

Following this line of thinking, exploration practices can be verbal or silent, driven by the body and performative actions. Linell insists that "situation-transcending" phenomena precede any interaction. I, therefore, suggest that framing the collaborative act means providing resources for it, and, in turn, the collaboration will be incrementally transformed through the mode of explorative collaboration. Linell argues that research on communicative activity types could be used to ask questions that cut across unhelpful disciplinary boundaries and encourage inquiry that studies interpersonal and institutional interaction problems to find activity types and communicative projects as solutions to institutional demands ([43], p. 462).

The concept of "participatory space of action" [36] (pp. 95-99) opens a dynamic space of action. In educational institutions, power will be exercised for the simple reason that teachers will have a mandate, a call or a task; therefore, an educational setting will always delimit what is possible for the teacher to do and not do. How an activity will develop depends on the teacher, the children participating, the material and the cultural traditions. A participatory space of action is opened if, for example, collaborative exploration is facilitated and extended. When shared explorative activities begin, a participatory space is opened with some particular styles or modes of action. Bakhtin writes, "We learn to cast our speech in generic forms, and when hearing other's speech, we guess it is a genre from the very first word" ([42], p. 79). Bakhtin's object of study was primarily literary texts, but he also served as a schoolteacher, and his essay "The Problem of the Speech Genres" [42] can be read through the lens of dialogic pedagogy. In his essay, he deals with the difference between language as a self-contained semiotic system (Saussurean linguistics) and language 
as a living dialog, understood as fluidity between language systems (translinguistics). He argues that the literature draws on genres that exist in communication, in the living dialog, what he calls primary genres. According to Bakhtin [42], any understanding of live speech and utterances is inherently responsive; the listener becomes the speaker. Those who speak will be oriented toward an actively responsive understanding. This addressivity will be part of the speaker's speech plan [42]. When a teacher is responsive to the child's world, to a gesture, an utterance, a movement or a mode of action, it follows that, in a mode of exploration, the teacher takes into account the background of the child or the immediate event. Teachers' contextual knowledge of children's experiences, such as their sympathies and antipathies, will be taken into consideration when the teachers position themselves, enacting language genres and pedagogical styles. Therefore, collaborative exploration indicates a mode of action with specific features, as pointed out above. As Hutt [39] found, exploration is a mode of action categorized as investigation and inspection but can, over time, move and transform between the epistemic behavior of exploration and the ludic mode of engagement. Following Bakhtin's view of language as communication genres [42], I see collaborative exploration as a primary genre, where both children and adults navigate a landscape of utterances by sharing the same place and situation but meeting up as different bodies with different histories.

To further explain what collaborative exploration can mean as a pedagogical style-a pedagogical positioning of the teacher-I will draw on Bakhtin's metaphor of the loophole, as it can signify a dialogical understanding of pedagogy as dynamic. Through this metaphor, Bakhtin indicates that a loophole signifies a side glance, or a shift of focus, where the person (the hero) can be ambiguous to events and even to his own writings about loopholes ([45], pp. 233-234). The metaphor presents pedagogy as movement, process and change. The loophole indicates an esthetic shape of a teacher's movement and maneuvers. Moreover, the metaphor implies the possibility for a teacher to adjust to the multitude of voices and events taking place in practice. Central modes in pedagogical actions will be enacted through the lived body [3]. This means that the teacher's environment is not a realm of separate objects, but rather that teachers are already involved in landscapes through their bodies being positioned in place and space [46], in activities, in relation to people. Persons are bodies positioning themselves in certain ways, in certain places, and always in relation to something or someone. Being bodies involves movements, sensations, using artifacts, utterances, materiality and symbols. In a pedagogical activity, the children and teachers are already involved in these components, which constitute conditions for the co-creation of meaning and for discourses [3]. The characteristics of pedagogical practices that facilitate collaborative exploration include openness, inquiry, collaboration, curiosity, multiple ways of knowledge, process orientation, co-creation of meaning, improvisation and variation [3].

\section{Illustration: Teacher's Style in Collaborative Exploration \\ 6.1. Method, Ethics and Analysis}

The following illustration is based on an excerpt from empirical observational data, an event related by a teacher-an artist working in a kindergarten in an art project about rewilding nature-a participatory art project. The art project lasted for one year (2019-2020), following nature's seasons and working with children and staff to open the senses, to move, to explore and to express through children's photos, stories and drawings. The teacherartist, was also a research assistant in an ongoing research project about exploration and cultural formation in kindergarten. The information was provided to parents in suitable languages, and consent was received for the teacher-artist to inhabit this double role, giving the research project access to written notes from the teaching arts project. The project's documentation was produced in a series of 16 excursions, with 60 written pages in total. An additional notebook consisted of stories about the teacher's dialogs, observations, and reflections. The illustration to be presented is a narrative reconstructed from observational data from this notebook. The research project followed the art project, but the data extracted 
for research purposes were limited to the research assistant/teacher-artist participant's observational data (written notes) to avoid the distribution of personally-identifying photos. The head of the kindergarten obtained consent from parents and checked the anonymity of the data before they were transmitted for research purposes.

The trustworthiness of the observational data and descriptions given by the teacher/ research assistant were validated through the preparation procedures of the ethical committee and at regular meeting points during the participatory fieldwork. Over the year, we met 14 times for dialogs and inquiries to better understand the impact of weather landscapes, the children and the pedagogy of the early years' institutions. A total of 18 children, all four years of age when the project started, and two additional teachers joined the excursions.

The narrative was rewritten by the author and validated by the teacher, following the methodological procedure outlined by Barbara Czarniawska [47]. Seven steps are followed in the analysis; 1 . The teacher and researchers both followed how the stories were made, 2. The teacher wrote the first version of the stories, 3 . The researchers provoked more stories over 14 meeting points; these versions were written down both by the teacher and the researcher, 4 . Together the teacher and the researcher interpreted the stories in dialogs; what do the stories tell us? 5 . The researcher deconstructed selected stories, 6 . The researcher put together new versions of selected stories based on contextual information given over time, 7 . These new stories were validated by the teacher and put together with other stories and with other information. The narrative text is considered to belong to other texts; in such a dialogical view, the researcher looks for clues in the narrative texts, including conversations with the teacher ([47], p. 663). This procedure elicited various narratives where the teacher's modes of action as dialogical, engaged, and collaborative oriented with the children became obvious [48]. The following story was selected for illustration and analysis. The narrative was rewritten by the author and validated by the teacher, following the methodological procedure outlined by Barbara Czarniawska [47].

\subsection{The Story of What It Means to Be Alive}

How can we know that we are alive; what does it mean to be alive? These questions came up in a conversation I had with the children one day, and my immediate answer to them was that we must breathe to live. I found a feather, and the children could try to breathe on the feather to check if they were alive. All the children in the group made the feather move by breathing on it, and we could with relief establish that all of us were alive. Several more questions about what was alive and what was not came up, and it was not easy to find good answers to all their questions. We, therefore, agreed that we would go out into the woods the next day to find out if we could find anything alive there. It was winter, and a light snow cover covered the ground, so I was not quite sure what would be the result of our little expedition the next day. We could not expect to find small insects. We did not go that far, only about $100 \mathrm{~m}$, right outside the fence in the kindergarten, to a small wood. We stopped at one of the big trees there. "Is the tree alive?" I asked. It became quiet. Everyone looked like they were listening to something. However, we did not hear any breathing sounds from the tree, so maybe the tree does not breathe, maybe the tree did not live? Some of the children went close to a tree, touched it, listened and started sniffing the bark. "Is the tree breathing?" I asked and gently touched the bark of the tree. The children did not respond immediately, but then a boy wondered if he heard a mouse breathing. We listened again, and another child stated that the tree could not breathe because it does not have a mouth. "Maybe it can breathe in other ways?" I suggested. "Maybe through the leaves?" However, there were no leaves on the trees since it was winter, so I could not prove myself right at that moment. We, therefore, instead started to feel the moss, and after a while, we moved on to a small ridge. I suggested we lie down for a while to think about what it meant to be alive. We lay down in star format and breathed deeply together. "I think the trees rest in the winter", I said while lying there. "I think they rest, as we do now. When spring comes, and the leaves return to the trees, we can see that the tree is alive." 
We breathed deeply in and out for a little while longer, and we agreed that we were still breathing and that we believed that the forest was breathing slowly in the winter.

\subsection{Components and Features of Pedagogical Style in the Narrative Event}

Analyzing the story following a dialogic approach, where bodily signs and positioning the body are valid as speech utterances [43], open insights into practices. Furthermore, the analysis follows components highlighted in the "Exploration as dialogical engagement model" [3], validating teachers' actions and initiatives, children's responses and initiatives, place, movement, sensation and time. These clues and components made it possible to identify features of the pedagogical culture and the teacher's style. By this approach, a surface structure of a signature pedagogy [23] was highlighted; specific ways of asking and answering, ways of approaching, taking the initiative and withdrawing. Components and conditions refer to relatively constant characteristics of the practices in this kindergarten. These components in culture create conditions for teaching practices. A pedagogical style is a continuous practice discovered within cultural practices [44], and features of pedagogical style refer to modes of action, movements and positionings.

The above analysis illustrates collaborative exploration by highlighting 11 components and conditions in the educational culture and features of the teacher's pedagogical style.

\subsection{Culture of Excursion Inside and Outside of Kindergarten}

In the case of kindergarten, there was established a culture of excursions as a regular activity (Table 1, number 1). Availability to various components afforded by local natural landscape area, as well as the culture of discovering and rediscovering processes and material in nature. A variation of activities evolved over time, some of them spontaneously (finding a feather and breathe) and others planned (the follow-up excursion into the woods the next day). Consequently, walking alongside children, paying attention to their movements and utterances and material and artifacts available in place and landscape were a pedagogical style of the teacher. As Hutt [39] found, exploration is a mode of action categorized as investigation and inspection, movement and transformations in-between an epistemic behavior of exploration and the ludic mode of engagement. The event described above unfolds what happened when a responsive teacher followed up children's curiosity about what it means to be alive.

The culture was an open curriculum in teachers' alertness to children's initiatives and enactment of responsiveness (Table 1, numbers 2 and 4). The teacher responded immediately to what it means to be alive, and a dialogical conversation evolved over days. The case has similarities with the visions for Froebel's "Kindergarten", where children experience the cycles of nature and the cosmos of the ecological environment. Froebel's vision included reciprocity where the teacher could learn from the children, and the children could learn from the teacher [31].

The teacher's mode of action was a whole-body sensation approach, as we can see in his encouragement to blow the feather, smell the tree and feel the moss. There was established a culture of shared movement and attention (Table 1, numbers 3 and 8 ). When they stopped at one of the big trees, it became quiet: The teacher reports that everyone looked like they were listening to something, but they did not hear any breathing sounds from the tree, so they started to wonder, touch, listen and sniff the bark to explore. The teacher and the children were bodies positioning themselves and engaged in relation to the tree and each other. This is what Froebel called the invisible third [13,31]. They were bodies involved in movements and sensations $[14,46]$. 
Table 1. Components and features of teachers' pedagogy in the narrative event.

\begin{tabular}{cc}
\hline \multicolumn{1}{c}{ Components and Conditions } \\
\hline $1 \quad$ Culture of excursion as a regular activity inside and \\
outside of kindergarten
\end{tabular}

Culture of open curriculum in the sense of teachers' alertness to children's initiatives and enactment of responsiveness

3 Culture of shared movement and attention
Culture of open curriculum in the sense of flexible time management

Features of Pedagogical Style

Walking alongside children, paying attention to their movements and utterances ("What does it mean to be alive?") as well as place and landscape (found a feather)

Teacher responds immediately to children's initiative and curiosity: "We must breathe to live".

Teacher picks up the feather and demonstrates by blowing on the feather and inviting the children to blow on it to check if they can breathe, make the feather move as sins of being alive

Teacher acknowledges the range of questions from children first by attempting to answer and then promising to search for evidence of life in the woods the next day

Finding some of the questions from children difficult to answer properly; negotiating and agreeing upon further investigations

Teacher reveals uncertainty: "It was winter, and a light snow cover covered the ground, so I was not quite sure what would be the result of our little expedition the next day."

Culture of the open curriculum in the sense of being open to teachers' knowledge and willing to contribute to expanding children's worlds, experience and knowledge

7

8 Culture of whole-body sensation approach
Stopping by a tree, the teacher asks the children, "is the tree alive?" (shared exploration)

Teacher encourages and allows children to listen, smell, touch and feel the tree. Later, the teacher encourages lying down in the moss, to feel the ground and taking deep breaths to feel the body being alive
9 Culture of picking up on children's play imagination and meaning-making

10

Culture of picking up on children's search for scientific knowledge
When a child can hear a mouse breathing, the teacher takes the imaginative suggestion seriously and listens once more.

When a child suggests that a tree cannot breathe because the tree does not have a mouth, the teacher takes the search for truth seriously and suggests that there are other ways that trees breathe through their leaves

Since this event took place in the winter, there were no leaves, so the statement could not be proven at this particular event through experience and needs to be further followed up at another stage of the natural life cycle
Cultures for living in the reality of natural cycles. Nature conditions what is possible to experience
There was established a culture of dialog and negotiation (Table 1, number 5). When the teacher and the children listened to find out whether a tree can breathe, one of the children stated that: the tree cannot breathe because it does not have a mouth. The teacher suggested: Maybe it can breathe in other ways? Maybe through the leaves? However, there were no leaves on the trees since it was winter, so the teacher could not prove himself right at that moment. He now allowed uncertainty in the dialog, and by this feature, he established a culture of uncertainty (Table 1 , number 6). To allow uncertainty in education can allow exploration. As Hutt and her team indicate, the point is not for the teacher to take over but rather to highlight the opportunity to expand the child's knowledge by exploring novel objects or ideas [40]. The teacher needed to search for new knowledge to respond to the child; how was it possible to prove to the children that a tree without leaves and a mouth could still be alive. This was not only difficult to understand, but it was also complicated for the teacher to explain. This space of uncertainty and openness inspired children's imagination. A child could hear the breath of a mouse. 
The teacher took this utterance seriously, and this indicates that there was established a culture of picking up on children's play imagination and meaning-making (Table 1, number 9). To give attention to the fantasy (for the child, it may be a fact) of hearing a mouse's breath that cold winter day is a symbolic play and pretense mode of action. This mode of pretense action was in this narrative is interwoven with another utterance from another child. When the child stated that a tree could not breathe because it does not have a mouth, the teacher also took the child's search for scientific knowledge seriously. Further exploration was necessary and realized later. This feature of practice indicates a culture of picking up on children's search for scientific knowledge (Table 1, number 10).

Finally, there was established a culture for living in the reality of nature cycles (Table 1, number 11). This teacher practiced what Froebel suggested; the teacher should encourage imagination and invite to a mode of action characterized by a curiosity about life forms and the cycles of nature [32]. Nature conditioned what was possible to experience. In the cold winter weather, the teacher suggested they lie down for a while to think about what it meant to be alive. He positioned the bodies in a star format and created a shared moment where they breathed deeply together.

These features of the pedagogical style are characterized by a deep understanding of the pedagogical task. The teacher positioned himself between responsibility to all children in the group and the group dynamic, which implied managing both the time and place.

\section{Conclusions}

The formulations of collaborative exploration as a signature pedagogy of the early childhood teacher are still tentative and preliminary and, as such, need to be further substantialized through future empirical work. In this article, I have suggested that collaborative exploration can be considered a signature pedagogy suitable for early years education. To substantiate and ground my argument, I first presented a concern about the worldwide "down-schooling" tendency and argued for an alternative approach through philosophical, historical and contemporary research.

Following central components from early pedagogics for the early years, it was established that the ideals were not used for transmitting knowledge from teacher to child, nor were punishment and strict discipline. On the contrary, 17th and 18th-century thinking opposed an instrumental and strict approach to education and argued for walking alongside children with playfulness to guide them and help them to discover.

Following Bakhtin, I adopted an organic and relational epistemological paradigm to strengthen the argument that collaborative exploration has features of an early childhood teacher's ideal practice. Such an ideal holds the promise of a sustainable future, as collaborative exploration simultaneously takes children's imagination and play seriously while paving the ground for following up on children's curiosity and endurance in investigating and searching for scientific truths about the world in which they live. A pedagogy of collaborative exploration will support resilience and innovation because it acknowledges uncertainty and drives meaning-making and the continual pursuit to find answers and solutions.

A signature pedagogy is understood as a set of assumptions about how best to use certain forms of knowledge and skills. This article demonstrates a surface structure characterized by specific ways of asking and answering, approaching, taking initiative and withdrawing. The example case, a narrative event about what it means to be alive, illustrated a culture for open-ended curriculum. Here, we could see how the teacher attempted to validate children's play and imagination as well as their continuous meaningmaking and search for the coherent scientific truth about the world in which they live. This suggests that a pedagogy of collaborative exploration goes beyond the dichotomies of play-based or learning-based curriculum and of seeing ECEC ideals as either child- or adultcentered; rather, a pedagogy of collaborative exploration acknowledges that pedagogy implies uncertainty. Therefore, a central feature of the positioning of a teacher needs to be movement and maneuvering between a complex mix of demands, conditions and 
initiatives. Features of the pedagogical style include attentiveness, shared meaning-making alongside children, acknowledgment of diverse forms of knowledge and maneuvering between children's play imagination and their search for scientific truths [49,50]. Moreover, there must be a deep understanding of the pedagogical task, whereby the teacher balances the responsibility to every child in the group and the group dynamic, managing both time and place (chronotopes) [43] in a whole-body approach. In a whole-body approach, the teacher focuses on relations to each person in the group as well as to the sensational world, which can include both human and non-human relations [51,52].

The article reveals a deep structure of the early childhood teacher's ideal pedagogy, a set of assumptions about how to use knowledge and implicit structures, such as attitudes, values and dispositions, found in the literature, which provide a foundation for ECEC pedagogy. Comenius' philosophy, as well as Froebel's arguments and contributions, arose in the 17th and 18th centuries in opposition to the Cartesian view of the divide between mind and body. Children's sensations and perception of reality-and how understanding and meaning-making are developed through sensation, experience and action-are crucial for their growth and development. This view is supported by various researchers from various fields, including brain research, play and design, as well as developmental psychology, some of which are presented here.

Following Shulman's [23] advice of identifying effective and wise practices in the teaching profession, I draw further on dialogism, a philosophical tool allowing utterances to be responsive and entangled in history and future orientations, as every utterance is also an utterance to someone. A Bakhtinian dialogic approach also allows considering attitudes, values and dispositions in the analysis. The features of teacher practices when engaging in explorative activities with children are identified through a Bakhtin-inspired analysis, where conditions are seen as cultures and features are seen as positioned in time and place [43]. I suggest that that the teacher needs to maneuver between using one's own knowledge and being responsive to the child's context and initiatives. Such a pedagogical positioning can be considered a style of collaborative exploration. In a Bakhtinian sense, such a style involves the whole body as a child's utterances can be moved, as well as verbal. Awareness of children's imaginative play as well as serious exploration will be a hallmark of a teacher's engagement.

Collaborative exploration can grow through negotiations and responsiveness to contexts and relations. The collaborative explorative genre follows up on and explores the discourse of shared endeavors, but just as important is the realization that the genre goes beyond mere talking. Establishing a pedagogical genre for collaborative exploration entails the whole spectrum of bodily expressions, from the song, dance and movements to gestures and signs indicating communication. It will also involve shared attention, curiosity, manipulation or problem-solving using artifacts or materials. Alternatively, collaborative exploration could mean shared moments of togetherness, as illustrated in the narrative when the teacher and the children laid down in the moss to breathe together to explore what it means to be alive.

The recognition of the collaborative exploration of a future-oriented pedagogy could be a driver of social sustainability, as we must learn to think and act differently to reach all the goals of sustainability. Both policymakers and teachers must be loyal to nature as well as to the next generation of humans to enable deep involvement in meaning-making, imagination and finding answers, as illustrated by the example case and supported in research [51] and global policy [52]. Both the teacher in the narrative, as well as Froebel's visions for kindergarten, indicated that children should align with the cycles of nature and the ecological environment. For education to bring about a future we desire, we need to remind ourselves that we are not just "creatures of the eye". The world takes place outside of a screen and a chair, and we are full-bodied beings with the capacity to explore and experience the world through all of our senses.

Since social sustainability is often overlooked in the discourse of sustainability, the impact of this article lies in the conceptualization and the argument for collaborative explo- 
ration as a signature of the ECEC teacher working towards goals of sustainability. Social sustainability in ECEC is a process for creating places and practices that promote wellbeing, meaning-making, growth and engagement for life and the living, the entanglements of the social, cultural and natural worlds. Quality education in ECEC, such as giving the best conditions for collaborative exploration, will, following the arguments in this article, be the best investment any country can do in the name of sustainability.

We need to further develop a pedagogy that is attentive to what it means to grow up in the Anthropocene epoch [4]. Collaborative exploration is, at its core, a profound binding of holistic awareness and pedagogical style, a hallmark of the early childhood profession. Therefore, additional studies should go along two main lines; The first of which could systematically ground the arguments given in this article in previous research in a broad scope. This could be in the existing educational, psychological, philosophical and creativity (Arts and innovation) literature. It could also be from an economic perspective, as it is anticipated that collaborative exploration could enhance the quality of life and education and thereby sustain societies. The second line recommends novel opportunities for pedagogical innovations and experiments on collaborative exploration in teacher education and in professional development. As teachers are keystones in educational change and improvement, it is urgent that teachers can acquire knowledge, understandings, and practices of collaborative exploration. Sustainability thinking and practice need insights from a field with a long tradition of supporting children's growth and development in ways that recognize the force, creativity and promise embedded in collaborative exploration.

Funding: This research was funded by the Research Council Norway, connected with the Kindergarten Knowledge Centre for Systemic Research on Diversity and Sustainable Futures (KINDknow Centre), Western Norway University of Applied Sciences, with grant number 275575.

Institutional Review Board Statement: The study, Exploration and Cultural Formation-Nomade, was conducted according to the guidelines of the Declaration of Helsinki, and approved by Norsk Senter for Forskningsdata (NSD) and the ethics board of HVL Meldeskjema 530501, date of approval: 20.03.2019.

Informed Consent Statement: Informed consent was obtained from all participants in the study, parents gave consent on the behalf of their child. Sensitivity was given to children's own consent in the everyday activities.

Data Availability Statement: The dataset underpinning the case developed for this article is not readily available because photos, drawings and stories cannot be shared without further concent from partcipants. Ethnographic observational notes and narrative inquiry notes are written in Norwegian. On request, translated and anonymized data can be made available for reviwers or editor.

Acknowledgments: I want to acknowledge the teacher-artist for work on ethnographic descriptions and for systematic dialogues and narrative inquiry throughout the project and the research group "Conditions for children as explorers". I would also like to thank the reviewers for their valuable, constructive criticism, which pushed my writings forward.

Conflicts of Interest: The author declares no conflict of interest, as the funders had no role in the design of the study; in the collection, analyses or interpretation of data; in the writing of the manuscript; or in the decision to publish the results.

\section{References}

1. Thyssen, G.; Grosvenor, I. Learning to make sense: Interdisciplinary perspectives on sensory education and embodied enculturation. Senses Soc. 2019, 14, 119-130. [CrossRef]

2. Nilsson, M.; Ferholt, B.; Lecusay, R. The playing-exploring child: Reconceptualizing the relationship between play and learning in early childhood education. Contemp. Issues Early Child. 2018, 19, 213-245. [CrossRef]

3. Ødegaard, E.E. Dialogical engagement and the co-creation of cultures of exploration. In Exploration and Cultural Formation; Hedegaard, M., Ødegaard, E.E., Eds.; Springer Nature: Basingstoke, UK, 2020.

4. Wals, A.E.J. Sustainability by default: Co-creating care and relationality through early childhood education. Int. J. Early Child. 2017, 49, 155-164. [CrossRef] 
5. Bingham, S.; Whitebread, D. School readiness in Europe: Issues and evidence. In International Handbook of Early Childhood Education; Fleer, M., van Oers, B., Eds.; Springer: Berlin/Heidelberg, Germany, 2018; pp. 363-391.

6. Whitebread, D.; Kuvalja, M.; O'Connor, A. Quality in Early Childhood Education: An International Review and Guide for Policy Makers. 2015. Available online: https://www.wise-qatar.org/sites/default/files/asset/document/wiseresearch-7-cambridge11_17.pdf (accessed on 29 April 2021).

7. Bennett, J. Pedagogy in early childhood services with special reference to Nordic approaches. Psychol. Sci. Educ. 2010, 3, 16-21.

8. Bubikova-Moan, J.; Næss Hjetland, H.; Wollscheid, S. ECE teachers' views on play-based learning: A systematic review. Eur. Early Child. Educ. Res. J. 2019, 27, 776-800. [CrossRef]

9. Singer, D.; Singer, J.; D’Agostino, H.; DeLong, R. Children's pastimes and play in sixteen nations: Free-play declining? Am. J. Play 2008, 1, 2-7.

10. Csikszentmihalyi, M. Flow: The Psychology of Optimal Experience; Harper and Row: New York, NY, USA, 1990.

11. Gudiksen, S.; Skovbjerg, H.M. Framing Play Design; BIS Publishers: Amsterdam, The Netherlands, 2020.

12. Classen, C. Other ways to wisdom: Learning through the senses across cultures. Int. Rev. Educ. 1999, 45, 269-280. [CrossRef]

13. Eikset, A.; Ødegaard, E.E. Historical roots of exploration-Through a Fröbelian third space. In Exploration and Cultural Formation; Hedegaard, M., Ødegaard, E.E., Eds.; Springer Nature: Basingstoke, UK, 2020.

14. Moss, P. Alternative Narratives in Early Childhood: An Introduction for Students and Practitioners; Routledge: Milton Park, UK, 2019.

15. Pramling, N.; Wallerstedt, C.; Lagerlöf, P.; Björklund, C.; Kultti, A.; Palmér, H.; Magnusson, M.; Thulin, S.; Jonsson, A.; Pramling Samuelsson, I. Play-Responsive Teaching in Early Childhood Education; Springer: Berlin/Heidelberg, Germany, 2019.

16. Fleer, M. Pedagogical positioning in play-Teachers being inside and outside of children's imaginary play. Early Child Dev. Care 2015, 185, 1801-1814. [CrossRef]

17. Hakkarainen, P.; Brdikyt, M.; Jakkula, K.; Munter, H. Adult play guidance and children's play development in a narrative play-world. Eur. Early Child. Educ. Res. J. 2013, 21, 213-225. [CrossRef]

18. Devi, A.; Fleer, M.; Li, L. Preschool teachers' pedagogical positioning in relation to children's imaginative play. Early Child Dev. Care 2020, 1-13. [CrossRef]

19. United Nations. Sustainable Development Goals; Department of Economic and Social Affairs, 2015. Available online: https: //sdgs.un.org/goals (accessed on 29 April 2021).

20. Daelmans, B.; Darmstadt, G.L.; Lombardi, J.; Black, M.; Britto, P.R.; Lye, S.; Dua, T.; Bhutta, Z.A.; Richter, L.M. Early childhood development: The foundation of sustainable development. Lancet 2016, 389, 9-11. [CrossRef]

21. Pramling Samuelsson, I.; Park, E. How to educate children for sustainable learning and for a sustainable world. Int. J. Early Child. 2017, 49, 273-285. [CrossRef]

22. Nxumalo, F.; Pacini-Ketchabaw, V. 'Staying with the trouble' in child-insect-educator common worlds. Environ. Educ. Res. 2017, 23, 1414-1426. [CrossRef]

23. Shulman, V.L. Signature pedagogies in the professions. Daedulus 2005, 134, 52-59. [CrossRef]

24. Falk, B. A conversation with Lee Shulman-Signature pedagogies for teacher education: Defining our practices and rethinking our preparation. New Educ. 2006, 2, 73-82. [CrossRef]

25. Skauge, T.; Kvitastein, O.; Sjøvold Hansen, H. Samlerapport. Studenterfaringar med FLU/BLU-Reforma; Report of Students Experiences from Teacher Education Reform; Bergen University College: Bergen, Norway, 2017.

26. Fulková, E.; Bosansky, B.J.A. Comenius' legacy in pedagogy: Present and Future. In Johannes Amos Comenius-The Legacy to the Culture of Education; Chocholova, S., Pankova, M., Eds.; Academia: Praha, Czech Republic, 2009; pp. 169-176.

27. Capkova, D. JA Comenius's Orbis Pictus in its conception as a textbook for the universal education of children. Paedagog. Hist. 1970, 10, 5-27. [CrossRef]

28. Froebel, F.W.A. Autobiography of Friedrich Froebel_Letter to the Duke of Meiningen, 4th ed.; Emilie, M., Translator; Lim Swan Sonnenschein \& Co.: Bloomsbury, UK, 1986.

29. Wulff, B. Friedrich Fröbel_-Hans liv og Gerning; Athenæum: København, Denmark, 1945.

30. Froebel, F.W.A. Fredrich Froebel's Pedagogics of the Kindergarten, or, His Ideas Concerning the Play and Playthings of the Child; Jarvis, J., Translator; D. Appleton and Company: Boston, MA, USA, 1909; Volume 30.

31. Froebel, F. The Education of Man; Jarvis, J., Translator; A. Lovell \& Company: New York, NY, USA, 2005.

32. Frobel Institute. 1782-1982 Friedrich Froebel; Froebel Institute College Roehampton: London, UK, 1982.

33. Bruce, T. Early Childhood Practice: Fröbel Today; Sage: London, UK, 2012.

34. Aldrian, B.; Wachhorst, W. The urge to explore. Mech. Eng. 2004, 126, 37-38. [CrossRef]

35. $\mathrm{Hu}, \mathrm{A} . ;$ Ødegaard, E.E. Play and/or learning comparative analysis of dominant concepts in curriculum guidelines for ECE in Norway, Finland, China and Hong Kong. In Annual Review of Comparative and International Education. International Perspectives on Education and Society; Wiseman, A.W., Ed.; Emerald Publishing: Bingley, UK, 2019; Volume 37, pp. $207-224$.

36. Ødegaard, E.E. Narrative Meaning-Making in Preschool. Ph.D. Thesis, University of Gothenburg, Gothenburg, Sweden, 2007 ; p. 255.

37. Skoglund, R.I. Beyond bullying: Understanding children's exploration of inclusion and exclusion processes in kindergarten. In Children's Exploration and Cultural Formation; Hedegaard, M., Ødegaard, E.E., Eds.; Springer Nature: Basingstoke, UK, 2020; pp. 29-45.

38. Hutt, C. Exploration and play. In Play and Learning; Sutton-Smith, B., Ed.; Gardner Press: New York, NY, USA, 1979. 
39. Hutt, C. Toward a taxonomy and conceptual model of play. In Developmental Processes in Early Childhood; Hutt, S.J., Rogers, D.A., Hutt, C., Eds.; Routledge \& Kegan: London, UK, 1981.

40. Hutt, C.; Bhavnani, R. Predictions from play. Nature 1972, 237, 171-172. [CrossRef]

41. Ødegaard, E.E. A pedagogy of collaborative exploration-A case study of the transition from a monocultural entity in national celebration rituals to a multilayered informed pedagogical practice. In Qualitative Studies of Exploration in Childhood Transitions: Cultures of Play and Learning; Hedegaard, M., Fleer, M., Ødegaard, E.E., Sørensen, H.V., Eds.; Bloomsbury: London, UK, 2021.

42. Bakhtin, M.M. The problem of the speech genre. In Speech Genres and Other Late Essays; McGee, V.W., Translator; University of Texas Press: Austin, TX, USA, 1986; pp. 60-102.

43. Linell, P. Rethinking Language, Mind, and World Dialogically: Interactional and Contextual Theories of Human Sense-Making; Information Act Publishing: Charlotte, NC, USA, 2009.

44. Schei, T.B.; Ødegaard, E.E. Stories of style-Exploring teachers' self-staging with musical artefacts. In Exploring Lived Experiences: Narratives and Early Childhood; Garvis, S., Pramling, N., Eds.; Routledge: London, UK, 2017.

45. Bakhtin, M. Problems of Dostoevsky's Poetics, 2nd ed.; Rotsel, R.W., Translator; Ardis Publishing: New York, NY, USA, 1973.

46. Ingold, T. Being Alive: Essays on Movement, Knowledge and Description; Routledge: London, UK, 2011.

47. Czarniawska, B. The uses of narrative in social science research. In Handbook of Data Analysis; Hardy, M., Bryman, A., Eds.; Sage Publications: Thousand Oaks, CA, USA, 2004.

48. Ness, O.; Borg, M.; Semb, R.; Karlsson, B. "Walking alongside": Collaborative practices in mental health and substance use care. Int. J. Ment. Health Syst. 2014, 8, 55. [CrossRef]

49. Springgay, S.; Truman, S.E. Walking Methodologies in a More-Than-Human World: WalkingLab; Routledge: Milton Park, UK, 2018.

50. Myrstad, A.; Hackett, A.; Bartnæs, P. First Lines in the snow: Minor paths in the search for early childhood education for planetary wellbeing. Glob. Stud. Child. 2020, 1-13. [CrossRef]

51. Sanderud, J.R.; Gurholt, K.P.; Moe, V.F. “Winter children”: An ethnographically inspired study of children being-and-becoming well-versed in snow and ice. Sport Educ. Soc. 2019, 25, 960-971. [CrossRef]

52. UNESCO (United Nations Educational, Scientific and Cultural Organization). Futures of Education—Learning to Become; UNESCO Headquaters: Paris, France, 2019; Available online: https:/ /en.unesco.org/futuresofeducation/ (accessed on 29 April 2021). 